\title{
PROMOTING THE ‘E’ IN STEM
}

\author{
Sara Darwish \\ Kings College London (KCL) \\ London, UK \\ Sara.darwish@kcl.ac.uk
}

\author{
Mohamed Darwish \\ Brunel University London \\ Uxbridge, UK \\ Mohamed.darwish@brunel.ac.uk
}

\begin{abstract}
Science, Technology, Engineering, and Mathematics (STEM) has been growing initiative for the past twenty years, and many countries are attempting to make significant steps in its implementation. In this paper the link between STEM Education and STEM Occupation is highlighted. This link is very important when it comes to engineering discipline in general and power engineering in particular.
\end{abstract}

Index Terms-Power System Education - STEM Education STEM Occupation.

\section{INTRODUCTION}

The acronym STEM (Science, Technology, Engineering and Maths) has been widely used in the past decade. These subjects, referred to as STEM, are said to be at the heart of jobs driving our economy today $[1,2]$. As we move forward to an economic era that relies heavily on engineering and computer aided technology, we must ask ourselves as educators, if we are doing enough for our students who have already chosen engineering discipline as branch of STEM Education to both engage and encourage them to do well in in STEM Occupation.

In 2018, The House of Commons released a publication named 'Delivering STEM skills for the economy' and stated, "STEM skills are crucial for the UK's productivity, and a shortage of STEM skills in the workforce is one of our key economic problems." [2]. According to [1], a country in high supply of highly qualified scientists, technologists, engineers and mathematicians, is globally perceived as being crucial in securing economic prosperity. Does the UK today have a flood of highly qualified scientists, technologists, engineers and mathematicians? According to [3] there is a gap between how schools teach STEM subjects and the knowledge, skills and beliefs needed for occupations within STEM related fields.

\section{WHAT IS STEM?}

At its simplest, STEM is the acronym for Science, Technology, Engineering and Mathematics. In the nineties, the National Science Foundation conceived the acronym
STEM as an initiative to provide students with critical and analytical thinking skills, enabling them to become enhanced problem solvers [4]. The initiative came as a result of important historical events (the wars and launch of NASA, to name a few). The technologies both invented and implemented during the wars (which lead to scientists, mathematicians and engineers collaborating with the military) were considered by some to be immeasurable [5]. It is recognised that STEM falls into one of two domains: Occupation or Education [6]. It very important to look at both domains and then focus on what STEM education should look like, in order to ensure that it leads to a higher rate of students moving on to occupations within STEM.

\section{STEM OCCUPATION}

If 'STEM jobs' are key contributors to the productivity growth in most advanced economies [15], then what exactly is a STEM job? According to [2], despite noting that there is no universal definition, they define a STEM job as one that "..requires the application of science, technology, engineering and mathematics skills.". It is not clear whether a STEM job must require all four disciplines coming together to form a meta-disciplinary subject as the word 'and' in their definition would suggest. A list of occupations from 11 different sources were collected and used the following formula to test and see the probability of it being defined as a STEM field [6].

Where:

$$
p=\frac{n_{\mathrm{i}}-n_{e}}{N}
$$

$n_{i}=$ number of definitions where the discipline is included

$n_{e}=$ number of definitions where the discipline is explicitly excluded

$N=$ the total number of definitions

Any discipline with a probability (p) lying between $63.6 \%$ and $100 \%$ are regarded as being a 'high frequency' STEM field and disciplines with probabilities between $54.5 \%$ and $18.2 \%$ as 'medium-frequency' STEM fields. It is unclear as to 
why these exact percentages were chosen for each frequency. Nevertheless, the results by Koonce et al. showed that the high-frequency STEM fields which had a probability of $91.7 \%$ were occupations such as: chemical engineering, civil engineering, material engineering, aerospace engineering and electrical engineering, just to name a few (refer to Appendix A for the full list of occupations). If the UK government want to ensure that we have economic prosperity by having a high supply of qualified scientists, technologists, engineers and mathematicians to be able to compete against other growing economies [1], then perhaps the answer with what exactly a STEM occupation lies within exploring occupations that are or will be in demand within the UK (so a STEM occupation in this case could differ between each country as well as alter every decade). If each country has different skills and demands within their industries, then it can be understood why countries do not universally agree with a definition for STEM. Each country should define STEM occupations as to where there are gaps. In Australia, health professionals, agriculture and computing are officially all included within STEM, however Australia has a large workforce in health services and a small workforce in both manufacturing and engineering professions [16]. If nations are injecting a lot of money and spending time on STEM initiatives, perhaps the number of occupations covered within STEM should be limited to only cover that specific country's needs. According to a report by the EDF titled 'Jobs of the future', they predict 10,182,000 jobs will open between 2016 and 2023 stating that growth in core science, research, engineering and technology based jobs are expected to continue outpacing overall growth in employment. They provide a table (Appendix B) with a list of top 20 industries for core science, research, engineering and technology jobs (ranked by net requirement). A 2018 report named 'The Future of Jobs' by the World Economic Forum, grouped roles into 'stable', 'new' and 'redundant' (Appendix C). A lot of the roles listed as 'new' and 'stable' coincide with the roles seen in the table by the EDF report (Appendix B). Now that there is an understanding and clarity of STEM occupations or as the World Economic Forum refers to as 'Fourth Industrial Revolution jobs' (jobs which will help with the economic prosperity of our country), it is now possible to attempt to explore STEM education.

\section{STEM EDUCATION}

There is a current awareness on the importance of STEM skills and the lack of them in the workforce, not just in the UK but also across the globe [7]. As a result of this, many countries have started initiatives and attempted to introduce 'STEM education' to both primary and secondary schools. In the UK, a National STEM Director was appointed and created an action plan involving 11 action programmes [8]. The majority of the action programs relate to the improvement of Science and Mathematics teaching with not as much mention or priority given to Engineering and Design Technology [9]. What exactly is STEM education? Should Engineering and Technology within STEM, be favoured over Science and
Maths, or should they all be integrated together? To some, STEM Education is the study of each of the four disciplines separately [10]. To others, it is only STEM when all four disciplines are integrated into one to imitate the work of a scientist or engineer [11]. If the point of STEM education is to benefit the economy by enticing students to study STEM fields at a tertiary level, then which of the two (if any) is correct? According to [12], STEM Education can take more than one form and doesn't necessarily have to integrate all four disciplines into one every time. Based on earlier research [13], they have created what they refer to as 'a plane of STEM integration'.

The first level of STEM is known as 'Disciplinary'. This is where students are taught each discipline separately as shown in Fig. 1. The teaching of isolated subjects has traditionally been the norm to how students are taught [14]. A number of researchers claim that the main fundamental reason for avoiding teaching subjects (mostly STEM subjects) as individual subjects is that questions such as "Why are we learning this?" are avoided [11]. The issue of whether or not to integrate subjects when teaching has been a discussion point for a number of years. The idea of curriculum integration comes from awareness that real world problems are not separated into individual stand alone disciplines, as is currently taught. If STEM is to never be taught as disciplinary subjects then what would this look like? When should STEM as any form of integration first be taught?

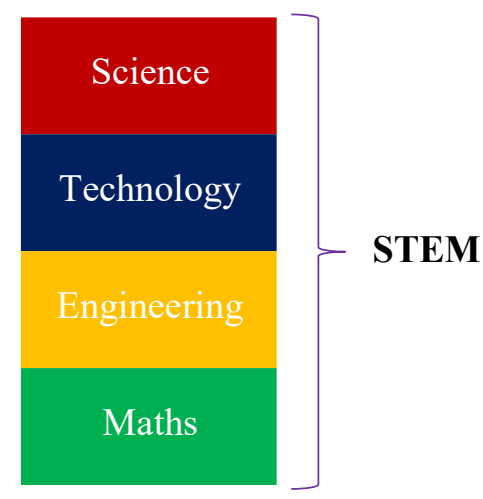

Fig. 1: Disciplinary STEM

The second level of STEM is known as 'Multidisciplinary' [12]. This is where students learn concepts and skills separately in each discipline but with a given common theme. In multidisciplinary approach each individual disciplinary course is allowed to retain its traditional strengths and content while allowing academics from each discipline to cooperate during module creation to enhance the interconnectedness of the modules. One way to do this is to include an interesting, engaging and relatable theme and teach each discipline separately but around this common theme. The ability to solve 'twenty first century/fourth industrial 
problems' requires a level of both multidisciplinary and interdisciplinary knowledge.

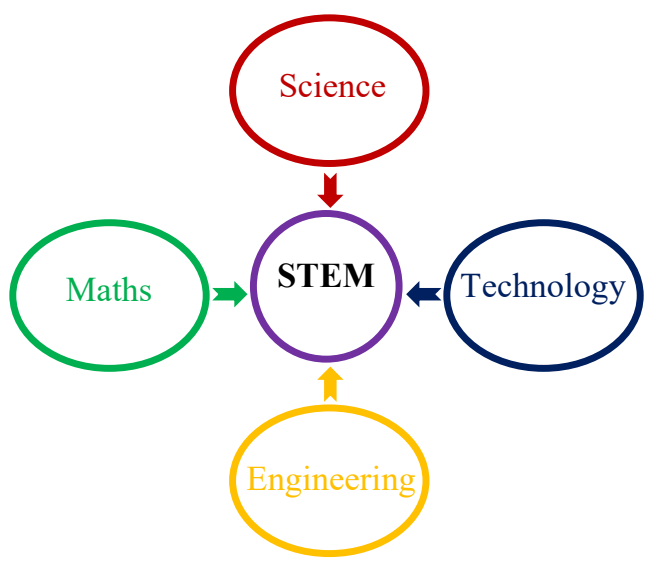

Fig.2: Multidisciplinary STEM

The third level of STEM on Vasquez's plane of integration is known as 'Interdisciplinary'. This is where students learn concepts and skills from two or more disciplines which are tightly linked. Students who engage in rich cross-disciplinary learning experiences will arguably have a deeper conceptual understanding of individual subjects such as Maths and Engineering.. Fig 3. Illustrates the concept of interdisciplinary STEM.

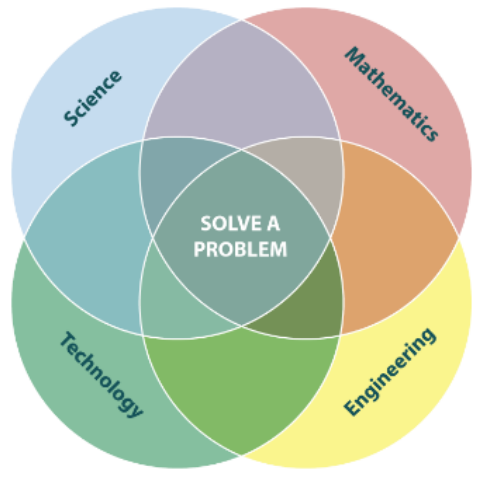

Fig.3: Interdisciplinary STEM

The fourth level of STEM is known as 'Transdisciplinary'. This is where students take part in real world problems or projects by integrating a vast range of disciplines. The difference between an interdisciplinary method of learning and a transdisciplinary method of learning is that with the interdisciplinary approach the grouping of closely related subjects, which are naturally linked, e.g. Engineering and Maths. An example of a transdisciplinary approach would be the integration of subjects such as Engineering and Music (where the subjects are not naturally interlinked). Fig. 4 illustrates the four types of STEM Education, and how they are related to each other's in terms of low/high integration and academic/non-academic participation.

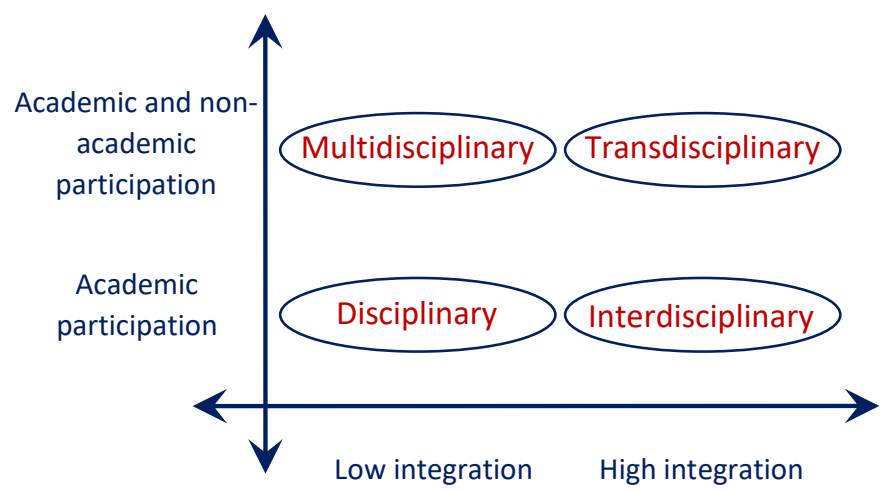

Fig.4: STEM Education

\section{PROMOTING THE 'E' IN STEM}

Unlike other professions, engineering is not visible to the general public. Engineering works behind-the-scenes and yet has a direct impact on every aspect of daily life. The main question is how do we promote Engineering at all levels of education? These are some of the steps required.

\section{A. Reform the engineering curriculum}

We keep hearing that engineering is only for those that are good at maths and science (based on entry requirement). By doing that, we are losing a large number of possible candidates. We need to show the creative parts of engineering and show that it is about solving real life problems not just solving $(\mathrm{x}-\mathrm{y})$ equations. We need curriculum reform. We need to do this to open up the pool of applicants that we attract from.

\section{B. Improve careers advice}

Universities need to do more to partner with industry and local schools to improve the careers advice. They need to provide students with hands-on, work-related experience.

\section{More financial support}

Many initiatives over the past 30 years have failed to significantly increase numbers and diversity. A recent report [16] estimated an increase of $£ 27 \mathrm{bn}$ of GDP if we could meet the need for engineers. Medical and nursing students, crucial to our country's wellbeing, receive financial support from government. A similar approach must be taken - slashing tuition fees for engineering courses and providing bursaries to help with living costs. 


\section{Industry collaborations}

EPSRC funds postgraduate students across the engineering and physical sciences, but without a supply of undergraduate students the task will be very harder. Industrial contribution to sponsor undergraduate students is vital.

Fig. 5 shows a route of promoting power engineering from very young ages at schools. Making sure that some of the STEM projects taught at school contains elements like renewable energy, how electricity is generated, etc. Fig 6. Shows a very simple experiment for primary school students which can be used to interest them in STEM-EngineeringPower Engineering.

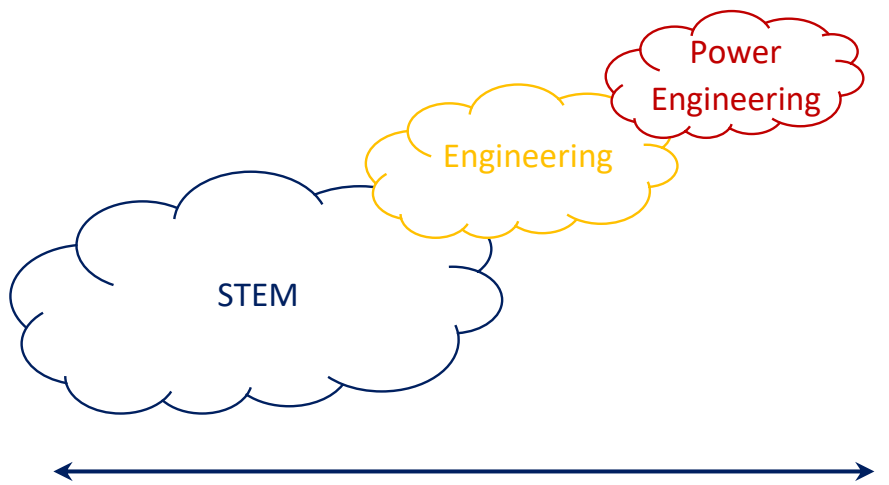

School ..... College ..... University

Fig.5: From STEM to Power Engineering

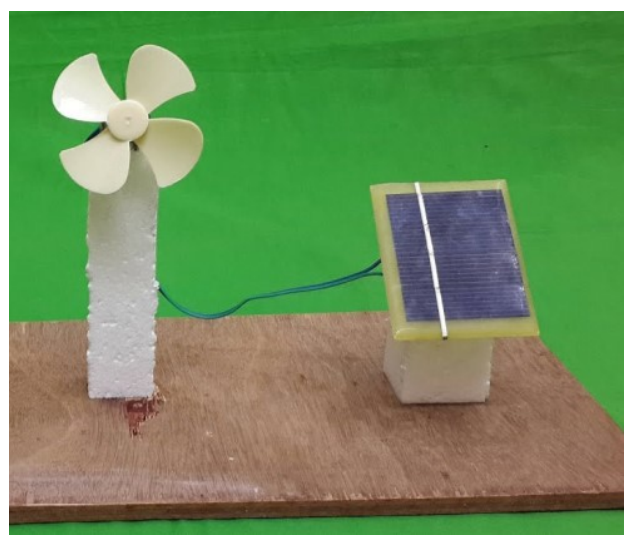

Fig.6: Simple primary school experiment

\section{CONCLUSIONS}

'STEM' is said to be at the heart of jobs driving our economy today, despite this $42 \%$ of employers have reported difficulty in recruiting STEM proficient staff. If the answer to ensuring a prosperous economy is by enabling that the UK has a handset of skill sufficient staff, then it would make sense to see what exactly STEM Education in the UK should look like, especially when the UK education system today is said to not provide young people with the STEM skills and knowledge needed for both university and industry. From engineering point of view, the main question is how to promote engineering within STEM subjects? Engineers use their wealth of knowledge, innovation and creativity in order to make things happen. Engineering graduates have immediate impact on the world once they leave universities. Within Engineering careers, power system engineers can work anywhere the electrical grid is concerned like generation and distribution companies. It is very important to have articulated string or path from STEM to Engineering to Power Engineering in our society.

\section{REFERENCES}

[1] Bell, D., "The reality of STEM education, design and technology teachers' perceptions: A phenomenographic study," International Journal of Technology and Design Education, 26(1), 61-79, 2016.

[2] House of Commons- Committee of Public Accounts. 2017-2019. Delivering STEM skills for the economy. Forty-Seventh Report of Session 2017-2019.

[3] Corlu, M.S., Capraro, R.M., Capraro, M.M., "Introducing STEM Education: Implications for Educating Our Teachers For the Age of Innovation" Journal of Education and Science, 2014.

[4] Blackley, S., Howell, J., "A STEM Narrative: 15 Years in the Making. Australian Journal of Teacher Education", 2015.

[5] White, D. W., "What is STEM education and why is it important?" Florida Association of Teacher Educators Journal, 1(14), 1-8, 2014.

[6] Koonce, D. A., Zhou, J., Anderson, C. D., Hening, D. A., \& Conley, M., "What is STEM?. American Society for Engineering Education Annual Conference Proceedings", 2011.

[7] Cuadra, E., \& Moreno, J. M., "Expanding opportunities and building competencies for young people: A new agenda for secondary education." Washington, DC: The World Bank, 2005.

[8] Williams, J. "STEM education: Proceed with caution", Design and Technology Education: an International Journal, 1(16), 26-35, 2011.

[9] Barlex, D., "Developing a technology curriculum". In P. J. Williams, A. Jones, \& C. Buntting (Eds.), "The future of technology education" (pp. 143-168). Dordrecht: Springer. (2015).

[10] Californian Department of Education. "Innovate: A Blueprint for Science, Technology, Engineering and Mathematics in California Public Education", A report by State Superintendent of Public Instruction Tom Torlakson's STEM Task Force, 2014.

[11] Morrison, J., \& Raymond Bartlett, V., "STEM as curriculum", Education Week, 23(March 4), 28-31, 2009.

[12] Vasquez, J., "STEM: beyond the acronym", Educational Leadership, Dec./Jan., 10-16. 2015.

[13] Vasquez, J., Sneider, C., \& Comer, M., "STEM lesson essentials, grades 3-8: integrating science, technology, engineering, and mathematics", Portsmouth, NH: Heinemann, 2013.

[14] Berry, M.R., Chalmers, C., Chandra, V., "STEM futures and practice, can we teach STEM in a more meaningful and integrated way?" In: Yu, Shengquan (Ed.) 2nd International STEM in Education Conference, 24-27 November, Beijing, China, 2012.

[15] Deming, David and Kadeem Noray, "STEM Careers and Technological Change", NBER Working Paper 25065, 2018.

[16] Marginson, S., Tytler, R., Freeman, B., \& Roberts, K., "STEM: Country comparisons", Melbourne: Australian Council of Learned Academies, 2013.

[17] Seritan, G. C., Enache, B. A., Porumb, R., Argatu, F. C., Adochiei, F. C., \& Vasilik, V., "Improvement of Teaching Activities In Higher 
Education". Revue Roumaine Des Sciences Techniques-Serie Electrotechnique Et Energetique, 63(4), 437-440, 2018. 